\title{
A experimentação como facilitadora de ensino: pesquisa-ação em ensino de ciências no ensino fundamental
}

Esta pesquisa realizou atividades experimentais nas aulas de ciências naturais, como uma ferramenta de ensino. $\mathrm{O}$ artigo apresenta resultados de pesquisa com a questão: a metodologia da experimentação contribui para os alunos do 20 ano do ensino fundamental desenvolverem o pensamento científico?. Para tal, teve como objetivo geral analisar a experimentação através da pesquisa-ação como estratégia de ensino para as aulas de ciências do 20 ano do Ensino Fundamental. Os objetivos específicos foram: aplicar a pesquisa-ação no desenvolvimento de trabalhos em sala de aula; pesquisar a experimentação como método de ensino trabalhar a aproximação do conteúdo estudado à realidade do aluno; provocar o interesse dos alunos do 2o ano do Ensino Fundamental pelo conteúdo estudado; analisar a evolução intelectual do professor pesquisador e dos alunos. Pesquisa de cunho qualitativo (COUTINHO, 2018), com os referenciais da pesquisa-ação (FRANCO, 2005; TRIPP, 2005) e apoiada em autores como Carvalho (1998; 2004), Espinoza (2010) e Astolfi et al. (1998). Como instrumento, utilizou a aprendizagem por projeto (BENDER, 2014) e foi desenvolvida, com crianças do segundo ano do Ensino Fundamental, com idade entre 7 e 8 anos. 0 resultado foi a constatação que a construção do conhecimento foi facilitada porque as atividades experimentais propiciaram aos alunos, a compreensão da teoria. 0 envolvimento nas atividades, possibilitou o trabalho em grupo e aproximou os alunos dos processos, práticas e procedimentos da investigação científica, possibilitou que colocassem em prática, diferentes conhecimentos tácitos no intuito de obter resultados. Em seu caráter epistemológico, a pesquisa-ação é uma ferramenta que privilegia a voz dos participantes e abre caminho para a construção do conhecimento.

\section{Experimentation as a facilitator for education: action research in science education in the second year of fundamental education}

This research conducted experimental activities in natural science classes as a teaching tool. The article presents research results with the question: Does the methodology of experimentation contribute to the students of the 2 nd year of elementary school to develop scientific thinking?. To this study, the general objective was to analyze experimentation through action research as a teaching strategy for science classes in the 2nd year of elementary school. The specific objectives were: To apply action research in the development of classroom work; research experimentation as a teaching method; work the approximation of the studied content to the student's reality; provoke the interest of students of the 2 nd year of elementary school for the studied content; analyze the intellectual evolution of the research teacher and the students. Qualitative research (COUTINHO, 2018), with an action research approach (FRANCO, 2005; TRIPP, 2005) and supported by authors such as Carvalho (1998; 2004), Espinoza (2010) and Astolfi et al. (1998). As an instrument, it used learning by project (BENDER, 2014) and was developed with children of the second year of elementary school, aged between 7 and 8 years. The result was the finding that the construction of knowledge was facilitated because the experimental activities provided students with an understanding of the theory. The involvement in the activities made possible the group work and brought the students closer to the processes, practices and procedures of scientific research, allowed them to put into practice different tacit knowledge in order to obtain results. In its epistemological character, the action research is a tool that privileges the voice of the participants and opens the way for the construction of knowledge.

Keywords: Action research; Teaching by research; Experimental Activities.

Topic: Pedagogia (Educação Criança e Adolescente)

Reviewed anonymously in the process of blind peer.

Claudineide Santos de Jesus

Faculdade Amadeus, Brasil

http://lattes.cnpq.br/0756077392219145

http://orcid.org/0000-0002-0415-6817

claudineidecdnd@gmail.com

Maria Auxiliadora Santos (10)

Faculdade Amadeus, Brasil

http://lattes.cnpq.br/0913978196443527

http://orcid.org/0000-0002-6488-7849

auxiliadorasantos@uol.com.br
Received: 11/11/2019

Approved: $20 / 03 / 2020$
Referencing this:

JESUS, C. S.; SANTOS, M. A.. A experimentação como facilitadora de ensino: pesquisa-ação em ensino de ciências no ensino fundamental. Civicae, v.2, n.1, p.1-17, 2020. DOI: http://doi.org/10.6008/CBPC26746646.2020.001.0001 


\section{INTRODUÇÃO}

Atualmente, muitos professores ainda desenvolvem as atividades experimentais nas escolas como uma aula prática diferenciada das aulas expositivas de rotina. As aulas não possuem uma participação efetiva dos alunos, eles apenas seguem um roteio estabelecido pelo professor e os alunos não compreendem os objetivos de todas as ações que precisam realizar. Em decorrência desse fato, observa-se, uma crescente pressão dos órgãos governamentais para a mudança na metodologia do ensino de ciências naturais.

A escola é um ambiente de constantes construções, descobertas e disseminações de informações, então, o professor precisa mediar o processo de formação de maneira que desperte nos alunos o interesse de participar de forma ativa em cada uma das etapas. Na concepção enciclopédica de ensino de ciências, que, ainda é utilizada na maioria das escolas em Sergipe, a abordagem é do ensino tradicional, em que o professor é o centro do saber que é transmitido pelo texto e por demonstrações, utilizando experimentos. Nessa prática, o conteúdo ocupa um lugar de destaque e depende dos conhecimentos do professor e de sua capacidade para exposição. A necessidade de mudança ficou evidente quando a participação ativa do aluno foi valorizada e o ensino passou a ser centrado no aluno, evoluindo posteriormente para a valorização da construção do conhecimento e enfoque na aprendizagem. Nesse caso, os conteúdos se tornam objeto de ensino e é considerado que, para aprender é preciso oferecer aos alunos atividades em que possam refletir, fazer novas descobertas, formular perguntas, argumentar, elaborar possíveis respostas, fazer registros e divulgar seus achados. Surgiu, portanto, outra maneira de abordagem das experimentações nas aulas de ciências.

O presente estudo tem o intuito de realizar atividades experimentais nas aulas de ciências naturais, como uma importante ferramenta de ensino. A pesquisa analisa a experimentação no ensino de Ciências (CARVALHO, 1998, 2004; ESPINOZA, 2010; ASTOLFI et al., 1998). Dentro desse contexto, questionou-se: a experimentação pode contribuir para a formação do pensamento científico dos alunos do $2^{\circ}$ ano do ensino fundamental? Nesse sentido, o objetivo geral foi: analisar a experimentação através da pesquisa-ação como estratégia de ensino para as aulas de ciências do 20 ano do Ensino Fundamental. Os objetivos específicos foram: Aplicar a pesquisa-ação no desenvolvimento de trabalhos em sala de aula; pesquisar a experimentação como método de ensino; trabalhar a aproximação do conteúdo estudado à realidade do aluno; provocar o interesse dos alunos do 2 ㅇ ano do Ensino Fundamental pelo conteúdo estudado; analisar a evolução intelectual do professor pesquisador e dos alunos.

A pesquisa foi de cunho qualitativo (COUTINHO, 2018; LUDKE et al., 2017). Utilizou os referenciais da pesquisa-ação (FRANCO, 2005; TRIPP, 2005), da pesquisa narrativa (CLANDININ et al., 2015) e para elaboração do texto, Silva (2018). Foi desenvolvida, com crianças do Ensino Fundamental menor, $2^{\circ}$ ano, com idade entre de 7 e 8 anos, em uma escola da rede Municipal de ensino em Aracaju/SE. Os instrumentos de coleta de dados foram: entrevistas semiestruturadas e não estruturadas com alunos e professores e uma intervenção pedagógica, de acordo com os projetos de aprendizagem apresentados por Bender (2014). 


\section{REVISÃO TEÓRICA}

\section{Pesquisa-ação}

De acordo com Tripp (2005), a pesquisa-ação não tem um inventor conhecido, a atribuição de sua criação por Kurt Lewin (1946) se dá por uma publicação em que ele emprega o termo, pela primeira vez, mas pode ter sido por meio de um trabalho realizado em Viena, na Alemanha, em 1913 (ALTRICHTER et al., 1992). Posto isso, é possível perceber que existe pouca probabilidade de saber sua data e local de origem, porque as pessoas sempre pesquisaram a própria prática no sentido de aprimorá-la. A definição da pesquisa-ação também é complexa. Porque se apresenta como um processo natural, sob muitos aspectos diferentes e seu desenvolvimento se deu de maneira diferente para diferentes aplicações (TRIPP, 2005).

A pesquisa-ação educacional (FRANCO, 2005) é muito utilizada como estratégia para o desenvolvimento de professores e pesquisadores que usam suas pesquisas como instrumento na promoção da melhoria da qualidade do ensino e, em decorrência, o aprendizado de seus alunos. Para a autora, a pesquisa-ação é um dos muitos tipos de investigação-ação. A sua prática é aprimorada pela oscilação sistemática entre agir no campo da prática e investigar o que foi desenvolvido. Esse ciclo funciona assim: planejamento, implementação, descrição e avaliação de uma mudança que melhore a prática, adquirindo mais conhecimento no correr do processo, a respeito da prática e da própria investigação realizada (Figura 1).

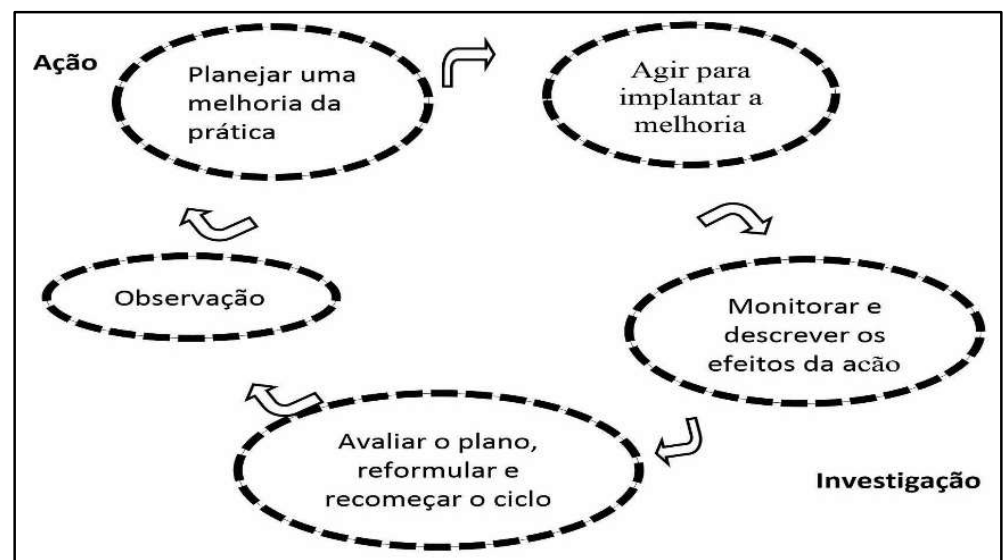

Figura 1: Diagrama: representação em cinco fases do ciclo básico da pesquisa-ação, com adaptação no acréscimo da observação no ciclo. Fonte: Tripp (2005). A observação é indispensável para diagnosticar onde a prática necessita de melhorias e sem ela o ato de planejar pode tornar-se ineficaz. Isso porque, a observação possibilita que o pesquisador conheça as dificuldades e o perfil dos sujeitos da pesquisa. Dessa maneira, o planejamento torna-se mais assertivo, possibilitando a melhoria tão almejada, da prática. Modificado pela autora, que incluiu a observação por considerar uma fase importante.

Segundo Tripp (2005) existe a denominação de muitos tipos diferentes de investigação-ação, porque algumas pessoas sem conhecimento das demais versões já existentes denominaram o mesmo ciclo e suas etapas de muitos modos diferentes. Também foram desenvolvidas versões para utilizações e situações particulares, porque há muitas maneiras diferentes de utilizar o ciclo e executar suas etapas. Desse modo, quando se utiliza processos de investigação-ação diferentes em suas etapas, os resultados se apresentam de forma diferenciada, bem como os seus relatos de acordo com o público a que ele se destina. 0 tipo de 
processo escolhido e como ele é utilizado depende dos objetivos e circunstâncias. O importante é que o tipo de investigação-ação utilizado seja adequado aos objetivos, práticas, participantes e contexto.

De acordo com Franco (2005), desde a sua origem a pesquisa-ação assume uma postura diferenciada diante do conhecimento, busca ao mesmo tempo conhecer e intervir na realidade que pesquisa. Essa parceria entre pesquisa e ação faz com que o pesquisador faça parte do universo pesquisado, o que anula a possibilidade de neutralidade e de controle das circunstâncias de pesquisa.

\section{Ensino de Ciências por investigação}

Ao observar a prática de professores ao ministrar suas aulas de ciências, compreende-se que muitos consideram importante a utilização da experimentação como uma estratégia de ensino em suas aulas. No entanto, é necessário pensar a experimentação além da aplicação de uma aula diferente. De acordo com Azevedo (2004), para ser considerada uma atividade de investigação, a ação do aluno não deve se limitar, apenas, ao trabalho de manipulação ou observação, precisa conter características de um trabalho científico. O aluno precisa refletir, discutir, explicar, relatar, construir suas hipóteses e as atividades devem fazer sentido para o aluno, para que ele compreenda o porquê está investigando determinado fenômeno.

Segundo Guimarães (2018), é importante ter em mente que os alunos poderão confirmar, ampliar e modificar sua própria visão de mundo a partir do desenvolvimento de posturas investigativas e mediação docente.

Criar condições para que os alunos digam o que pensam com convicção, argumentem com precisão e exponham suas ideias com persuasão (e não repetindo o que o professor disse) são objetivos a serem atingidos em todo ensino construtivista, mas que só pode ser alcançado através de um trabalho diário, perseverante e muito atento do professor. (CARVALHO, 1998).

Azevedo (2004) afirma que é fundamental que o professor apresente um problema, sobre o que está sendo estudado como ponto de partida, e constitui um aspecto fundamental para a criação de um novo conhecimento. A aprendizagem de procedimentos e atitudes, é tão importante, dentro de um processo de aprendizagem, quanto os conteúdos conceituais. O estudante precisa estar ativo na resolução de um problema, deve refletir, buscar informações e participar das etapas do processo que leve a resolução do problema que foi proposto. O professor deve alterar a sua postura, agindo como um guia e não apenas um transmissor do conhecimento. Para isso, deve utilizar como base o conhecimento que os alunos já possuem do seu contato cotidiano com o mundo. A experimentação fundamentada na resolução de problemas gera o interesse do aluno e incentiva sua participação de modo que ele inicie a produção do seu conhecimento por meio da interação entre pensar, sentir e fazer. A solução de problemas pode ser um instrumento para o desenvolver habilidades e capacidades, como: raciocínio, flexibilidade, astúcia, argumentação e ação. 0 processo de pensar, leva o aluno a construir, também, a sua autonomia.

\section{Experimentação}

Na busca por mudança de métodos do ensino de ciências, Espinoza (2010) relata que na década de 1970, desenvolveu-se em vários países do Ocidente uma modalidade denominada "redescoberta" [...] "que 
propunha aos alunos a realização de experiências com a esperança de que a manipulação de objetos e a observação dos fenômenos permitissem elaborar explicações mais próximas do pensamento científico". Evoluindo nessa questão, Astolfi et al. (1998), analisa as ciências experimentais como facilitadora do sucesso escolar e faz referência ao pensamento de Vigotski e considera [...] "as práticas experimentais como ocasiões de estimulação intelectual dos alunos na sua zona de proximidade de desenvolvimento, que ultrapassam as suas possibilidades conceituais, do momento, mas que apesar disso lhe é acessível, graças à mediação do professor, do grupo e das suas atividades".

De acordo com Brasil (2018), a área de Ciências da Natureza, precisa proporcionar aos alunos do Ensino Fundamental o acesso à multiplicidade de conhecimentos científicos gerados no decorrer da história. Assim, os alunos devem ser gradativamente estimulados e apoiados no planejamento e na realização cooperativa de atividades investigativas. Isso não significa realizar atividades seguindo um conjunto de etapas predefinidas, tampouco se restringir à manipulação de objetos ou realização de experimentos em laboratório.

Como bem nos assegura Silva (2017), a consecução de atividades experimentais requer mais dedicação e preparação docente, porque as práticas devem estar associadas ao que está sendo trabalhado em sala de aula. Para ultrapassar esta barreira, faz-se necessário uma busca de mais conhecimento para aperfeiçoamento profissional como leitura de trabalhos de especialistas na área, realização de pósgraduação, cursos, seminários, entre outros. Nesse contexto, fica claro que a preparação de atividades experimentais, demanda tempo e estudo, já que se torna fundamental pesquisar sobre como realizar tais atividades e preparar os materiais e equipamentos necessários, como também averiguar se há suficiente espaço disponível. Como são diversos os elementos, preparo de uma atividade experimental demanda tempo e se torna maior que o de uma aula expositiva tradicional, exigindo mais recursos e dedicação.

A referida autora afirma que o professor deve repensar a sua prática pedagógica e planejar atividades que se adequem à realidade do estudante, isso servirá de estímulo e o ajudará a compreender os conceitos e entender a ciência como construção histórica e saber prático; instigar a curiosidade e a criatividade do educando, no objetivo de capacitá-lo a fazer uso de informações e conhecimentos científicos para refletir o mundo que o envolve e solucionar problemas que the são apresentados. O professor precisa aplicar atividades experimentais para incentivar o aluno na formulação de questões sobre a realidade concreta, no teste das hipóteses levantadas, no debate de ideias e, assim, ele desenvolverá a capacidade de argumentar, numa postura crítica, investigativa e sensível à necessidade de intervir no ambiente onde vive.

\section{METODOLOGIA}

A pesquisa foi de cunho qualitativo (COUTINHO, 2018; LUDKE et al., 2017), narrativa (CLANDININ et al., 2015). Utilizou como abordagem a pesquisa-ação (FRANCO, 2005; TRIPP, 2005) e para elaboração do texto, Silva (2018). Foi desenvolvida, com crianças do Ensino Fundamental menor, $2^{\circ}$ ano, com faixa etária de 7 a 8 anos, em uma escola da rede Municipal de ensino em Aracaju/SE. Os instrumentos de coleta de dados foram: entrevistas com alunos e professores e uma intervenção pedagógica, de acordo com os projetos 
de aprendizagem apresentados por Bender (2014), dividida em 6 etapas compostas de atividades como: roda de conversa, leitura de textos, atividades experimentais, registros escritos, construção de um livro e realização de entrevistas.

\section{RESULTADOS}

\section{Ação pedagógica}

Em 2018, tive a oportunidade de fazer uma intervenção em uma escola da rede particular de ensino do Estado de Sergipe, com alunos do 20 ano do Ensino Fundamental, com faixa etária de 7 e 8 anos. A pesquisa buscava verificar como os experimentos utilizados pelo professor contribuem para o alcance de uma maior compreensão do conteúdo e percepção do aluno sobre a significância que determinado conhecimento científico estudado possui.

Na ocasião, o projeto desenvolvido foi: 'Seres Vivos: a importância dos fungos na produção dos alimentos'. O resultado foi a constatação que a utilização de atividade experimental desperta nos alunos maior interesse pelo conteúdo ensinado e torna a aprendizagem mais significativa para eles ao relacionar o conteúdo com o dia-a-dia. As atividades experimentais devem ser bem planejadas e direcionadas pelo professor para que os alunos compreendam bem qual é o objetivo da experiência e porque estão fazendo tal atividade. Então, após uma reflexão sobre os resultados do projeto anterior planejei, o atual projeto didático, buscando seguir as fases do ciclo básico da pesquisa-ação e pensando sobre a importância da utilização dos experimentos na escola.

\section{Desenvolvimento do projeto na escola}

O Projeto de Pesquisa, "Utilizando a experimentação como metodologia facilitadora de aprendizagem no ensino de Ciências", foi aplicado no 2o ano, turma B, no período vespertino de uma Escola Municipal, localizada na cidade de Aracaju/SE. A escola possuía 265 alunos, funcionava nos dois turnos, manhã e tarde e, na ocasião, oferecia Educação Infantil e Ensino Fundamental do $1^{\circ}$ ao $5^{\circ}$ ano. Atendia crianças com faixa etária entre 4 a 15 anos e funcionava com sete turmas no turno matutino e vespertino. A escola não tinha laboratório, por essa razão os experimentos foram desenvolvidos em sala de aula, utilizando materiais de fácil acesso e baixo custo. Foi utilizado o tema, OS FUNGOS, para desenvolver os experimentos, pois considerei a grande importância deles para o meio ambiente e utilização humana, além de ser um tema que as crianças associariam bem com situações vivenciadas em seu cotidiano.

Iniciei o trabalho com a apresentação de um cartaz com imagens de cogumelos, realizando perguntas para despertar a curiosidade dos alunos e incentivá-los a querer saber mais sobre o assunto. "Vocês conhecem esses seres vivos? Sabem como são chamados?". A maioria da turma reconheceu e respondeu que se tratava de cogumelos, pois já haviam visto em outros lugares. Respostas dos alunos: Aluno A: 'Já vi eles em uma árvore e também no desenho que assisti na TV. Aluno B: 'São fungos!'.

Então, perguntei em que locais eles poderiam ser encontrados. Alguns responderam na água, outros 
disseram na Floresta. Ao perguntar por que eles são importantes para o meio ambiente, os alunos afirmaram que não sabiam, nem sabiam como eles obtêm alimentos. A cada resposta que os alunos davam, a partir dos seus conhecimentos adquiridos no cotidiano, era explicado como tudo funcionava de maneira científica. De acordo com Moço et al. (2010), o tema a ser pesquisado precisa ser atraente. Não é recomendável escolher um tema que os alunos desconhecem e que esteja distante da sua realidade.

O tema escolhido objetivou atender às orientações dos especialistas, aproximando o conhecimento científico das ações desenvolvidas por eles no dia a dia. Além de despertar o interesse dos alunos pelo tema, as perguntas realizadas tiveram o intuito de verificar quais eram seus conhecimentos prévios sobre o assunto.

Segundo Gimenes (2010), os fungos possuem um reino próprio chamado Reino Fungi; não realiza a fotossíntese pois são aclorofilados; a reprodução pode ser assexuada, por meio de esporos (necessita de apenas um indivíduo para ocorrer e não cria variabilidade genética) e sexuada (necessita de dois indivíduos para ocorrer e ocasiona variabilidade genética); podem ser também unicelulares ou multicelulares, e são heterótrofos (sua nutrição ocorre por absorção). Popularmente conhecidos como cogumelos ou orelhas de pau, os fungos basidiomicetos, possuem estruturas de reprodução macroscópicas, podem ser encontrados em ambientes aquáticos e terrestres, em uma grande variedade de substratos e em diferentes biomas. Tem participação na decomposição da matéria orgânica e possuem ecologicamente uma grande importância, pois realizam a ciclagem de nutrientes.

\section{Pesquisa de informações}

Após esse momento, os alunos realizaram a leitura sobre os fungos (Figura 1), nos textos selecionados e disponibilizados: Santos (2015), Atlas visuais - plantas e Guia prático de Ciências. Esses textos traziam informações sobre o que são fungos; a ação de decomposição que eles realizam na natureza; o uso na produção de alimentos, medicamentos e as doenças causadas por eles. A leitura foi realizada coletivamente. Os alunos foram divididos em dois grupos, o que ajudou muito, já que eles estão na fase de alfabetização. Aqueles que sabiam ler, ajudaram os que não sabiam ou tinham dificuldades de realizá-la. Os textos eram curtos e com imagens, seguindo as orientações que os especialistas orientam para a faixa etária dos alunos.

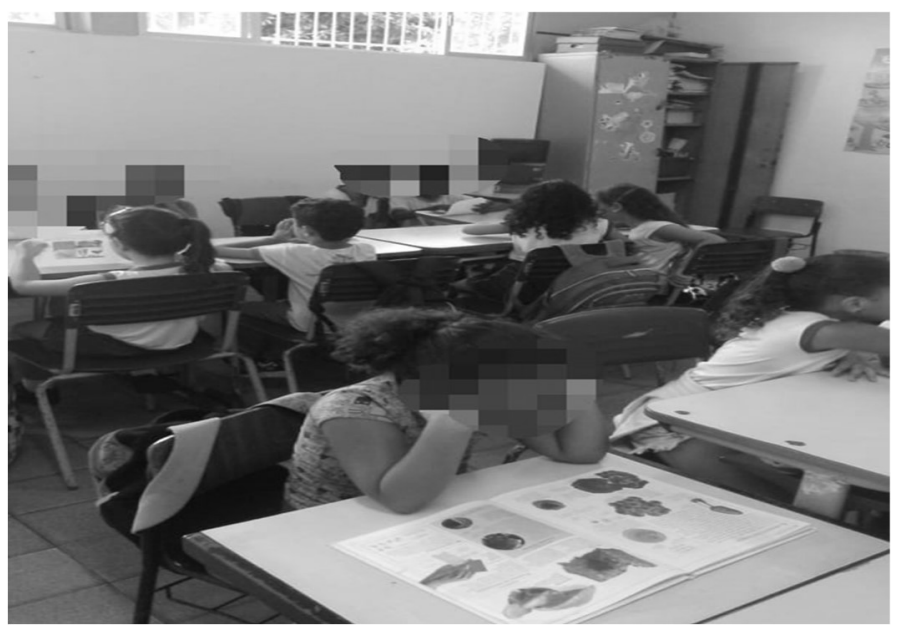

Figura 1: Alunos realizando a leitura dos textos sobre fungos. 
Moço et al. (2010) afirmam que ao entrar em contato com o texto, os alunos fazem a relação do que está sendo lido com o que já sabem. Nesse momento a mediação do professor é muito importante para ajudá-los a compreender o sentido dos escritos e lidar com as contradições entre os novos dados e o conhecimento que eles já possuem.

\section{Analisando o levantamento de hipóteses}

Em seguida, foi realizada a experiência do copo com água e papel, para que os alunos pudessem compreender melhor o que é matéria. Dessa forma, viram alguns exemplos de como a matéria pode ser encontrada na natureza, ou seja, em três estados físicos, sólido (papel), líquido (água), e gasoso (ar). Os alunos demonstraram muito interesse em participar da experiência. Foi colocada na mesa uma vasilha com água e dentro um copo de vidro. Os alunos colocaram um pedaço de papel amassado e empurraram para o fundo do copo, de maneira que o papel ficasse preso no fundo. Antes que eles mergulhassem o copo na vasilha com água, virado com a abertura do copo para baixo, perguntei, o que eles achavam que iria acontecer?. Aluno C: 'o papel ficará todo molhado!'.

A maioria da turma também acreditava que seria isso que iria ocorrer. Uma menor parte, disse que não iria molhar, porém, não sabiam dar nenhuma explicação para a sua afirmativa. Apenas o aluno $B$, disse: não vai molhar muito por causa das bolhas que saem do copo.

Ao mergulharem o copo na água e retirá-lo, notaram que o papel estava seco. Eles repetiram essa ação várias vezes para verem se o resultado seria diferente. Na maioria das vezes o papel saiu seco, em outras quando eles inclinavam um pouco o copo, saiam umas bolhas e a água molhava o papel. Então, questionei por que o papel às vezes molhava e outras não. Os alunos discutiram entre si e chegaram à conclusão que, quando as bolhas saiam a água sempre entrava. Então, perguntei o que estava dentro do copo para impedir a água de entrar e ao sair fazer aquelas bolhas. Aluno D: 'é o ar que fica dentro, por isso a água não pode entrar'. O aluno E, completou dizendo: 'se um sair (ar) o outro entra (água)'.

A partir dessa discussão comecei a explicar o conceito de matéria, e como ela pode ser encontrada na natureza em três estados físicos: sólido, líquido e gasoso. O que ficou bem mais fácil de compreender com a experiência. Entenderam que o copo era um exemplo de matéria no estado sólido, a água no estado líquido, e o ar no estado gasoso. Silva (2017) afirma que o professor deve utilizar as atividades experimentais como um importante recurso na formulação de questões sobre a realidade concreta, no teste das hipóteses levantadas, no debate de ideias e desenvolver no aluno a capacidade de argumentação, uma postura crítica e investigativa.

\section{Experiência com fungos}

A segunda atividade experimental foi a observação dos alimentos estragados e os saudáveis para que os alunos observassem, fizessem as comparações e levantassem hipóteses. Utilizei os seguintes materiais: pão, tomate e batata com bolor; frutas e verduras variadas; pratos descartáveis e luva plástica. Em seguida, ocorreu o momento de observação. Para isso, comecei expondo para a turma as amostras emboloradas de 
tomate, batata e pão; coloquei amostras de pães guardadas em lugares diferentes por quinze dias. A primeira amostra se tratava de um pedaço de pão colocado em lugar seco e com circulação de ar, outro pedaço de pão foi umedecido e colocado em um recipiente plástico, sendo lacrado e um terceiro na geladeira. Depois, essas amostras foram expostas. Usando lupas, os alunos observaram as diferenças entre as amostras. Eles gostaram muito de utilizar as lupas na experiência, principalmente as que tinham uma espécie de lanterna para ver melhor o objeto.

\section{Observação e registro}

Todos observaram as amostras e também as manipularam. Perceberam bem as diferenças entre elas, expressaram isso de forma oral e por meio de registro escrito, construindo uma tabela (Figura 2). Esse momento de observação das amostras de pães, proporcionou interação entre os alunos. Cada um expressava as características que tinha notado nas amostras, e outro colega acrescentava uma a mais que até o momento não tinha sido notada. Assim eles foram construindo a tabela.

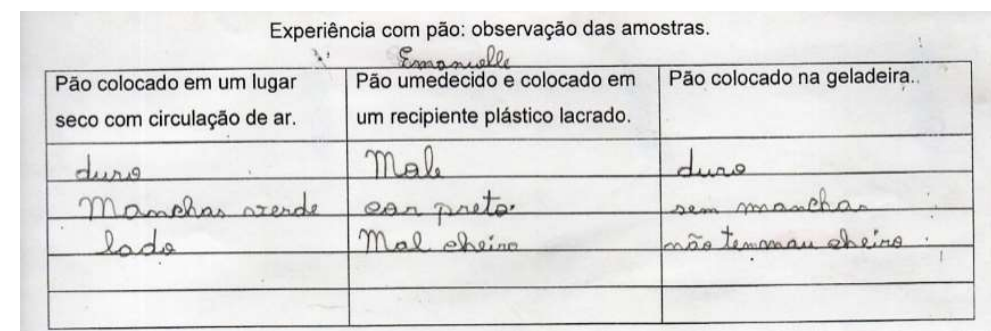

Figura 2: preenchida por aluna após a observação das amostras de Pães.

Os alunos realizaram o preenchimento da tabela, registrando as diferenças entre eles. $\mathrm{O}$ aluno $\mathrm{F}$, observando a amostra de pão umedecido: 'Esse aqui ficou muito podre, porque está molhado'. O aluno C, afirmou olhando para o pão colocado em um lugar seco com circulação de ar: 'Esse ficou com manchas verdes e o lado preto, porque não estava na geladeira como aquele'. Aluno E: 'Se guardar o pão na geladeira fica bom para comer! Aquele que está molhado ficou bem fedido e mais podre'. Ouvindo as opiniões dos alunos, fiz alguns questionamentos para estimulá-los a pensar. O que aconteceu com os pães para que eles ficassem com essa aparência? Aluno G: 'Os fungos estão comendo eles!'.

Todos os alunos concordaram com o colega. Então, expliquei que se tratava de um processo de decomposição, que é realizado pelos fungos. Segundo Dandolini (2013) esse processo é muito importante para a natureza, porque é por meio da decomposição que a matéria orgânica é absorvida, e elementos minerais, compostos químicos e outros são liberados ficando mais uma vez disponíveis no ambiente, podendo ser utilizado por outros organismos no ecossistema. Depois perguntei por que as amostras estavam tão diferentes umas das outras. $\mathrm{O}$ aluno $\mathrm{H}$ disse: 'Porque estavam em lugares diferentes'. Aluno I: 'Porque um estava molhado e outro não'. Aluno B: 'Porque os fungos não gostam do frio da geladeira. Por isso o pão que estava lá ficou bom'.

Por meio dessas comparações, os alunos entenderam que alguns fatores presentes na natureza são responsáveis por modificar a estrutura dos alimentos. De acordo com Dandolini (2013), a umidade elevada 
e as altas temperaturas são os responsáveis pela modificação dos alimentos. Esses fatores auxiliam na formação do bolor e consequentemente a degradação. Os fungos, então, se multiplicaram mais facilmente nas amostras do pão colocado em um lugar seco com circulação de ar, e no pão umedecido e colocado em um recipiente plástico e lacrado, por causa dos fatores favoráveis e a matéria orgânica que eles usaram para se alimentar, nesse caso o pão. Já o pão colocado na geladeira estava em baixa temperatura (refrigeração) fazendo com que os fungos fossem menos ativos. Por isso, os bolores não eram vistos nessa amostra.

De acordo com Stolarski (2015), as condições inadequadas de temperaturas, instalações, utensílios ou equipamentos, podem transmitir microrganismos (Pequenos corpos que só podem ser vistos, através de microscópio) para os alimentos, contaminando-os. É necessário manter o armazenamento correto dos alimentos para evitar as principais fontes de contaminação.

Segundo Pezarini et al. (2018), a argumentação é essencial para o processo de formação e desempenha uma importante função na construção do conhecimento científico. A argumentação aproxima a vivência escolar do contexto científico, garantindo um ensino coeso, e que possua aplicabilidade. Promover a construção da habilidade de persuasão no aluno é importante, e está em conformidade com as práticas científicas. Os alunos não devem apenas repetir palavras, precisam construir significados próprios, que possam ser cientificamente aceitáveis. Nesse momento, estimulei os alunos a observarem os alimentos de forma cuidadosa e atentar para as diferenças que surgiram após os alimentos estragarem, cor, textura, manchas, etc.. Enquanto eles observavam, perguntei: o que aconteceu para que as frutas ficassem com essa aparência?.

A experiência do pão com bolor foi excelente, pois ajudou muito na compreensão de que os fatores presentes na natureza são responsáveis por modificar a estrutura dos alimentos. Com a experiência, os alunos tiveram a oportunidade de ver que algumas informações que eles leram nos textos anteriormente, realmente ocorriam na prática.

\section{Registros}

As crianças realizaram registros escritos e por meio de desenhos, sobre o que aprenderam em relação à importância dos fungos para o meio ambiente e também utilização humana. As figuras 3, 4 e 5, mostram alguns registros feitos pelos alunos, de forma escrita e por meio do desenho. Na figura 3 a aluna regista, de forma escrita, as ações negativas e o uso dos fungos de forma positiva. Na figura 4, a aluna desenhou algumas utilizações dos fungos na produção de pães, vinho, e fabricação de medicamentos (representada pela imagem do dedo na figura). Já na figura 5, o aluno desenhou cogumelos, um tipo de fungo bem conhecido e abordado durante o desenvolvimento do projeto.

Astolfi et al. (1998) afirma que os registros são importantes para verificar o progresso em uma determinada atividade. Permite avaliar em que ponto se encontra as representações dos alunos e seus conhecimentos, bem como os procedimentos e ferramentas dominadas por eles. Além disso, a produção de registro torna o aluno sensível ao que foi construído e estruturado. 


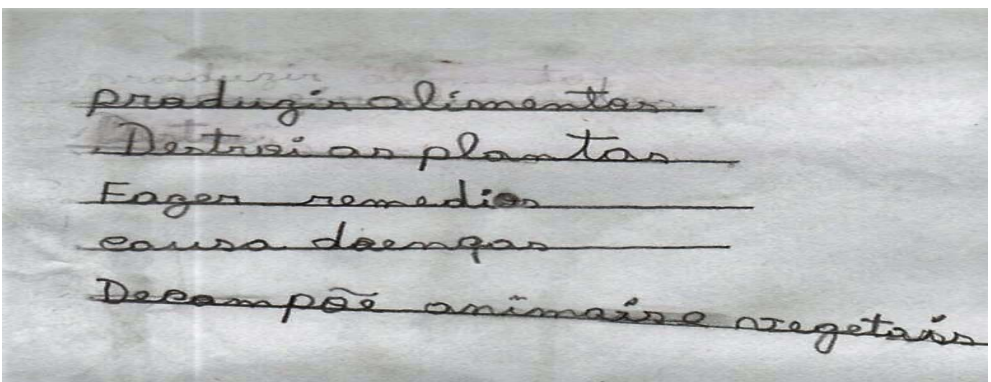

Figura 3: Ações negativas e positivas dos fungos.

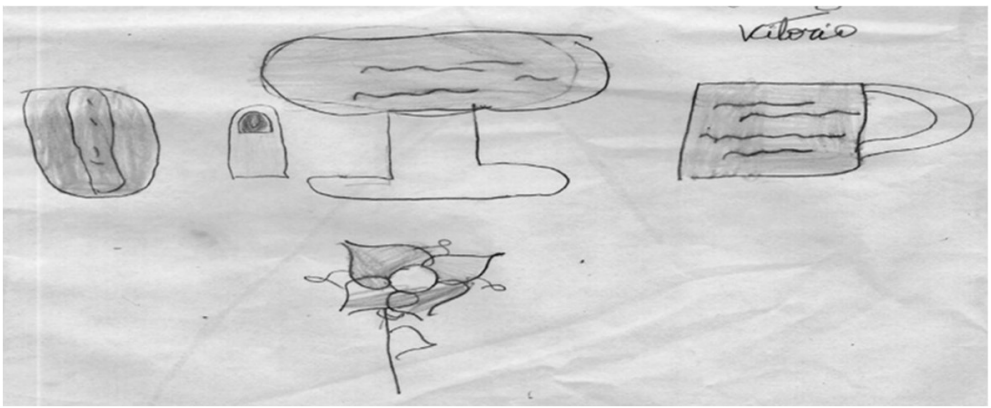

Figura 4: Uso dos fungos de forma positiva.

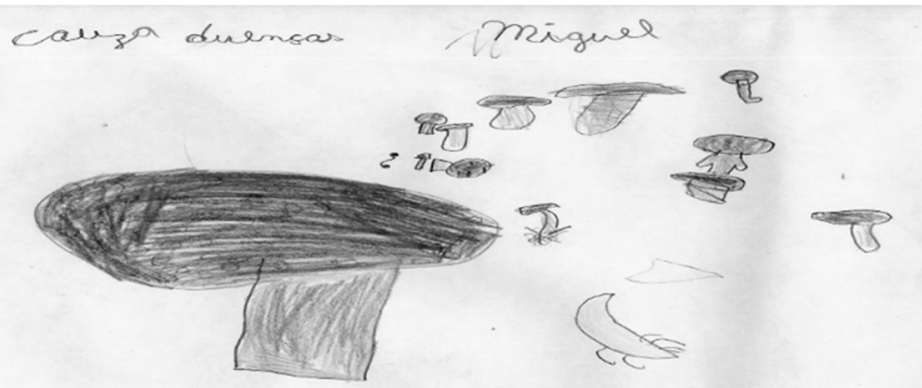

Figura 5: Registro por meio do desenho dos cogumelos, um fungo bem conhecido, que também é utilizado na alimentação.

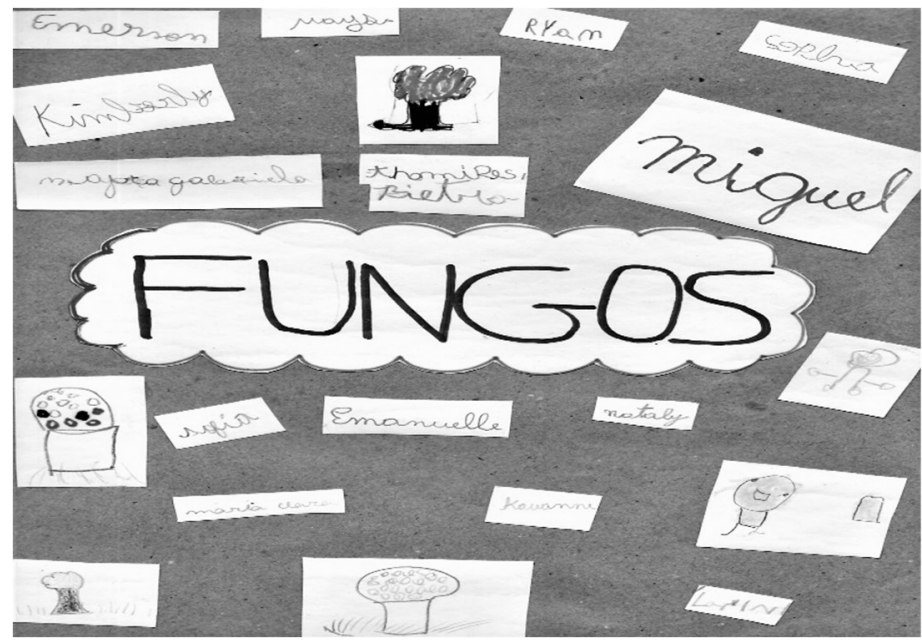

Figura 6: Finalização da capa do livro.

Após esse momento, houve uma discussão sobre a forma correta de armazenar os alimentos, para mantê-los frescos por um longo período. Os cuidados com a higiene pessoal para evitar doenças causadas por fungos. Depois de vivenciarem esses momentos, os alunos participaram da construção e organização de um livro (figura 6), contendo as produções escritas por eles, textos e imagens com informações que eles consideraram importantes colocar na produção. O livro ficou exposto na biblioteca para que outras turmas 
pudessem aprender mais sobre esses seres vivos tão importantes para o meio ambiente. Os alunos ficaram livres para criar, utilizando o conhecimento adquirido.

\section{Entrevista com os alunos: Grupo focal}

Foram realizadas entrevistas com vinte alunos que participaram do projeto, para saber como tinham sido as aulas de Ciências na escola, e o que eles acharam das experiências vivenciadas no projeto. Conforme afirma Gondim (2003), grupos focais é uma técnica de pesquisa que coleta dados por meio das interações grupais ou por meio de discussão de um tema sugerido pelo pesquisador. Essa técnica está em posição intermediária entre a observação participante e as entrevistas em profundidade. Também é entendida como um recurso para compreender o processo de construção das percepções, atitudes e interpretações sociais que os grupos humanos realizam. Em roda de conversa os alunos responderam às perguntas, demonstrando entusiasmo (Tabela 1).

Tabela 1: Perguntas feitas para a turma e as respostas dos alunos.

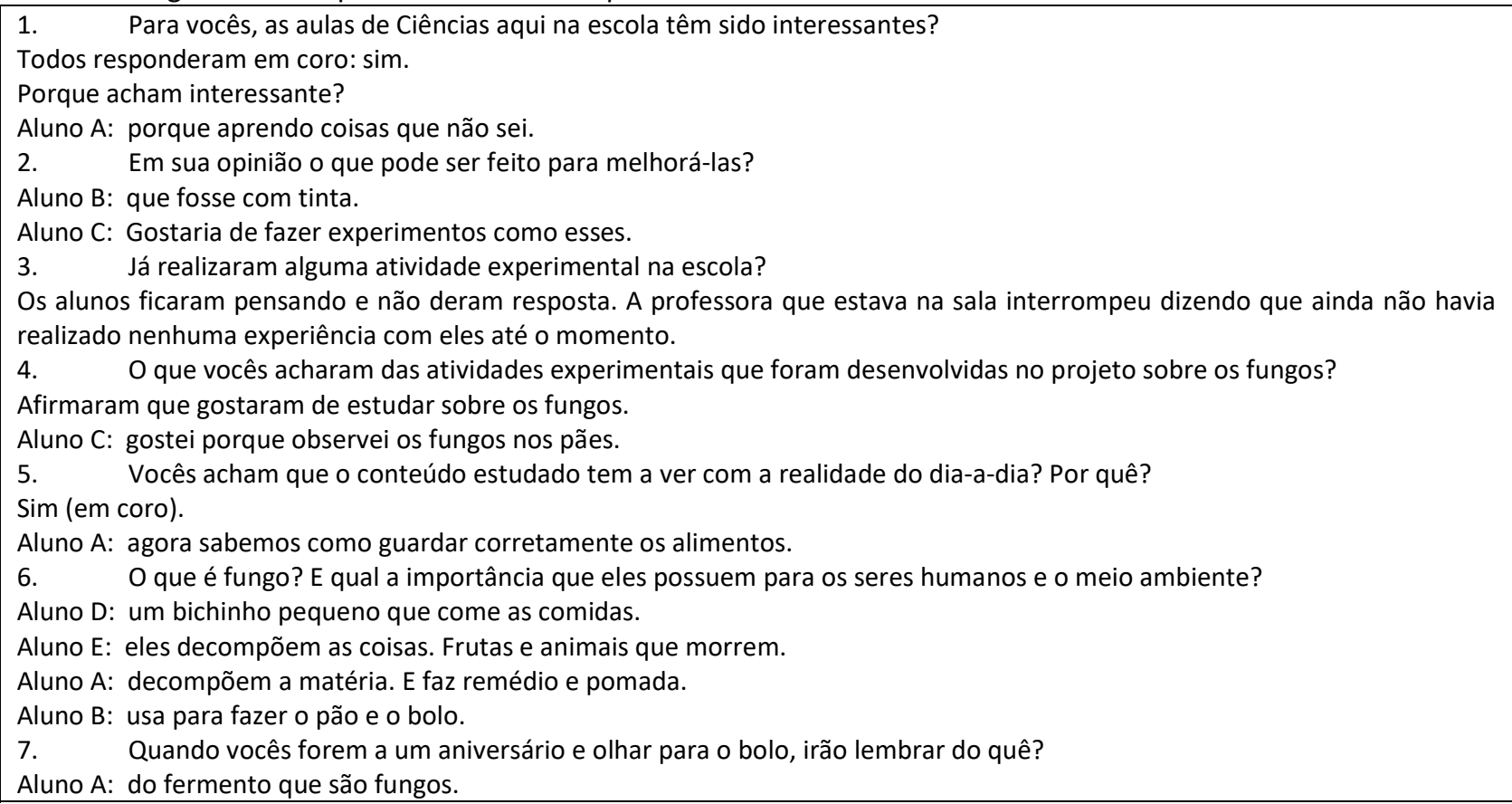

Foi realizada, também, uma entrevista com quatro professoras, objetivando conhecer o que elas pensam sobre a utilização de atividades experimentais no ensino de Ciências. O critério para a escolha de professoras de escola pública e particular para a realização das entrevistas, foram as observações feitas nas duas escolas.

\section{DISCUSSÃO}

\section{Elaboração do problema de pesquisa}

O problema de pesquisa foi elaborado com base em observações em sala de aula em um colégio particular e em uma escola pública. Nas observações foi perceptível que no colégio particular, a experimentação era tratada como uma aula diferenciada para atrair a atenção dos alunos. Esses alunos ao 
finalizar a experiência, muitas vezes, não conseguiam entender o motivo de tudo aquilo, nem ao menos entender a importância do que estava sendo estudado, pois não lhes era devidamente mostrado que o que está nas páginas dos livros faz parte do seu cotidiano e não é uma realidade distante. Já na escola pública a aula de Ciências, ocorreu apenas com o uso do livro didático. A professora fez a leitura, explicou e em seguida os alunos responderam às questões propostas no livro.

Azevedo (2004) afirma que dentro de um processo de ensino, a aprendizagem de procedimentos é tão importante quanto os conceitos e conteúdo. Para ele, o estudante deve estar ativo na resolução de um problema, precisa refletir, buscar informações e participar das etapas do processo que leve à solução do problema que foi proposto. Nesse processo, o professor deve agir como um guia, utilizando como base o conhecimento que os alunos já possuem, adquirido em seu cotidiano. A experimentação baseada na resolução de problemas desperta o interesse do aluno e estimula a sua participação. É através da interação entre refletir, sentir e fazer, que o aluno produz seu conhecimento e constrói a sua autonomia. Além disso, a solução de problemas pode ser um instrumento importante no desenvolvimento de habilidades e capacidades indispensáveis como: raciocínio, flexibilidade, astúcia, argumentação e ação.

\section{A pesquisa-ação}

Blackberry et al. (2019), pesquisadores da Universidade de Griffith, em Brisbane na Austrália, trabalharam com projetos aplicados em escolas procurando entender a importância do uso da pesquisa-ação para analisar o desenvolvimento intelectual dos estudantes e dos professores. Os autores afirmam que a pesquisa-ação possibilita o desenvolvimento de estratégias que ratificam a inovação das ações dos professores e a evolução da qualidade da aprendizagem dos estudantes. Consideram que a pesquisa-ação tem um caráter epistemológico, por ser uma ferramenta que privilegia a voz dos participantes e os caminhos para construção do conhecimento. Os autores sugerem que a pesquisa-ação capacita os participantes a desenvolverem ideias em seus projetos; indica possíveis ideias futuras e possibilita compartilhamento com colegas de equipe; garante que os participantes sejam encorajados a disseminarem seu trabalho com outros professore, ao invés de discutir, apenas com pesquisadores externos, de instituições de pesquisa. Afirmam, ainda, que a pesquisa-ação é uma ferramenta potente para iniciativas de pesquisa nas escolas.

Na ação utilizei a "aprendizagem baseada em projetos" que é um instrumento de ensino muito eficaz, que permite aos alunos investigar problemas do seu cotidiano e trabalhar coletivamente em busca de soluções para questões pesquisadas (BENDER, 2014). Para o autor, escolas de todo o mundo enfrentam dificuldades para desenvolver modelos de ensino que possuam melhor eficácia em relação aos já praticados. Isso ocorre devido ao período de orçamentos reduzidos enfrentado. Apesar das dificuldades enfrentadas pelas escolas, falta de materiais, estrutura inadequada, falta de equipamentos tecnológicos, entre outros, o professor criativo e que possua conhecimentos sobre aprendizagem baseada em projeto, pode realizar uma ação pedagógica que envolva seus alunos e resulte em um bom desenvolvimento de todos. 


\section{Ensino de ciências por investigação}

A pesquisa alcançou as diretrizes da BNCC (Base Nacional Comum Curricular) (BRASIL, 2018), que afirma ser importante organizar as situações de aprendizagem partindo de questões que sejam desafiadoras e reconheçam a diversidade cultural, estimulem o interesse e a curiosidade científica dos alunos e possibilitem a definição de problemas, levantem, analisem e representem resultados; comuniquem conclusões e proponham intervenções. Conhecimentos, competências e habilidades são estabelecidos, daquilo que se espera que os estudantes desenvolvam ao longo da escolaridade básica. Estabelece o conjunto de aprendizagens fundamentais ao desenvolvimento dos alunos em todas as etapas e modalidades da educação básica, que, por sua vez, deve ser bem planejada e organizada para a garantia de bons resultados.

\section{Experimentação}

De acordo com Silva (2017) somente os dados teóricos apresentados em sala de aula, através de aulas expositivas não são suficientes para despertar o interesse e a atenção dos alunos. De posse do conhecimento programático, os professores devem utilizar alguns recursos, como: realização de exercícios, trabalhos individuais e/ou em grupo e a realização de atividades experimentais. $\mathrm{O}$ envolvimento dos participantes na realização das atividades, exercita o trabalho em grupo, a divisão de tarefas e o atendimento às regras e procedimentos. Dessa maneira, para a obtenção de um determinado resultado são colocados em prática diversos conhecimentos adquiridos durante o desenvolvimento educacional.

Segundo Espinoza (2010), o professor precisa conduzir essas atividades de práticas experimentais de uma forma que envolva os alunos e desperte o interesse em participar do processo, por meio de diversas e variadas situações em que o aluno se sinta estimulado e capaz de ir em busca das respostas sobre as questões apresentadas pelo professor. É importante que o aluno encontre sentido no conteúdo que está sendo ensinado, entenda a aplicabilidade do conhecimento e perceba que a situação lhe diz respeito e não apenas estar disposto a satisfazer o desejo do professor. Nesse sentido, a experiência do pão com bolor foi excelente, pois ajudou muito na compreensão de que os fatores presentes na natureza são responsáveis por modificar a estrutura dos alimentos. Com a experiência, os alunos tiveram a oportunidade de ver que algumas informações que eles leram nos textos anteriormente, realmente ocorriam na prática.

\section{Entrevistas}

$\mathrm{Na}$ entrevista, as respostas fornecidas pelos alunos mostram que eles reconhecem que o ensino de Ciências Ihes proporciona novos conhecimentos. De acordo com Azevedo (2004), as atividades realizadas precisam fazer sentido para o aluno, para que possam compreender a importância de investigar determinado fenômeno. $\mathrm{O}$ aluno jamais deve pensar que as investigações e estudos desenvolvidos ficam restritos às 'paredes da escola', precisam perceber que devem levar o conhecimento adquirido para ser utilizado em todos os espaços que eles possam chegar e principalmente, ser utilizável em seu dia a dia. 
As atividades experimentais foram uma novidade para eles, já que as aulas de ciências até o determinado momento ocorreram apenas com o uso do livro didático. O contato com os materiais utilizados nas experimentações, os procedimentos e as observações de amostras de alimentos sofrendo ações de fungos, trouxe uma aproximação do aluno ao conteúdo, despertou o interesse pelo que estava sendo estudado e lhes proporcionou uma aproximação aos principais processos, práticas e procedimentos utilizados em uma investigação científica.

Foi realizada, também, uma entrevista com quatro professoras, objetivando conhecer o que elas pensam sobre a utilização de atividades experimentais no ensino de Ciências. O critério para a escolha de professoras de escola pública e particular para a realização das entrevistas, foram as observações feitas nas duas escolas.

As respostas das professoras durante a entrevista, mostram que todas consideram importante a realização de atividades experimentais no ensino de Ciências. Afirmam desenvolver essas atividades com frequência e consideram que as experiências facilitam a compreensão e assimilação do conteúdo estudado. Além de despertar a curiosidade cientifica e o prazer de aprender o conteúdo que está sendo abordado. Jesus et al. (2018) afirmam que a realização de atividade experimental é um instrumento importante para aguçar a percepção e estimular o raciocínio lógico de forma prazerosa.

De acordo com Brasil (2018) é fundamental que os alunos sejam estimulados e apoiados no planejamento e na realização de atividades investigativas e partilhar os resultados dessas investigações. Essas atividades não devem seguir um conjunto de etapas predefinidas, nem se limitar à mera manipulação de objetos. Longe disso, conjectura organizar as situações de aprendizagem partindo de questões que sejam desafiadoras, reconhecendo a diversidade cultural dos alunos e estimulando o interesse e a curiosidade científica.

Segundo Silva (2017), quando as atividades experimentais são desenvolvidas de maneira adequada, os alunos compreendem a teoria e participam do processo de construção do conhecimento, colocando em prática conhecimentos adquiridos ao longo do desenvolvimento educacional. Todavia, a realização de atividades experimentais exige mais dedicação e preparação do professor, para que suas práticas estejam relacionadas ao que está sendo apresentado em sala de aula. A preparação de atividades experimentais, exige tempo e estudo, pois é fundamental a realização de pesquisas, sobre como realizar tais atividades e levantar o quantitativo de materiais e equipamentos, além de verificar se o espaço disponível é suficiente. Diante desses elementos, o tempo de preparo de uma atividade experimental, torna-se maior que o de uma aula expositiva tradicional, exigindo mais recursos e dedicação. Assim, se faz necessário uma busca de mais conhecimento para aperfeiçoamento profissional.

As professoras também afirmaram que não é necessário gastar muito, tampouco ter um laboratório de Ciências para realizar atividade experimental, pois materiais do cotidiano podem ser utilizados. Em relação às dificuldades enfrentadas para preparar ou realizar uma aula experimental, citaram, quantidade de alunos por turma, falta de materiais e espaço apropriado, e domínio do conteúdo. De acordo com Silva (2017), o professor precisa repensar a sua prática pedagógica e pesquisar metodologias que se adaptem à realidade 
do aluno e a partir daí, promover atividades experimentais. É preciso superar as dificuldades e criar a cada dia novas possibilidades de aprender de forma significativa. O professor não pode se deixar ser vencido pelo desânimo ou comodismo.

\section{CONCLUSÕES}

A pesquisa-ação é importante para o ensino, pois possibilita o envolvimento do pesquisador e dos pesquisados na busca de soluções para os problemas. Essa interação, proporciona, no ambiente escolar, aprendizagem para ambos, além de aproximar a teoria da prática. A pesquisa-ação possibilitou para os alunos o desenvolvimento autônomo e tiveram oportunidade de construir o conhecimento e não apenas receber informações. Para mim enquanto pesquisadora, tive a oportunidade de refletir de forma crítica sobre a prática que foi desenvolvida.

Nas atividades desenvolvidas, os alunos tiveram uma participação efetiva, demostraram interesse pelo conteúdo estudado e estiveram ativos em todo processo. Tiveram a oportunidade de observar, refletir, criar hipóteses, discutir e compreender a teoria, ou seja, participaram do processo de construção do conhecimento. O professor deve atuar como um guia, e sua mediação exige dedicação na busca do conhecimento necessário e mais tempo de preparação das atividades a ser desenvolvidas. Houve participação ativa dos alunos, e após a avaliação, por meio dos registros, constatei evidências de resultados saindo dos ciclos de pesquisa-ação, indicando evolução do perfil conceitual.

Ao analisar as atividades desenvolvidas no projeto, conclui-se que a experimentação, contribuiu para a formação de base do pensamento científico dos alunos, de forma bem articulada. A experimentação para ser eficaz, precisa ser bem planejada e organizada, com metodologias que se adaptem à realidade do aluno. De maneira que possa aproximá-lo do conteúdo, despertando o interesse pelo que está sendo estudado e Ihe proporcione o contato com os principais processos, práticas e procedimentos utilizados em uma investigação científica.

\section{REFERÊNCIAS}

AZEVEDO, M. C. P. S.. Ensino por investigação:

Problematizando as atividades em sala de aula. In: CARVALHO, A. M. P.. Ensino de Ciências Unindo a pesquisa e a prática. São Paulo: Pioneira Thomson Learning, 2004.

ASTOLFI, J.-P.; PETERFALVI, B.; VÉRIN, A.. Como as crianças aprendem as Ciências. Lisboa: Retz, 1998.

BLACKBERRY, G.; KAEARNEY, J.; GLEN, M.. Developing na interpretive learning framework for understanding action research projects. Educational Action Research, v.27, n.2, p.318-330, 2019.

BRASIL. Ministério da Educação. Base nacional comum curricular: Ensino Fundamental. Brasília: MEC, 2018.

BENDER, W. N.. Aprendizagem baseada em projetos: educação diferenciada para o século XXI. Porto Alegre: Penso, 2014.
CARVALHO, A. M. P.. Ciências no ensino fundamental: o conhecimento físico. São Paulo: Scipione, 2004.

CARVALHO, A. M. P.. Ciências no ensino fundamental: o conhecimento físico. São Paulo: Scipione, 1998.

CLANDININ, D. J.; CONNELLY, M.. Pesquisa narrativa: experiências e história na pesquisa qualitativa. 2 ed. Uberlândia: EDUFU, 2015.

COUTINHO, C. P.. Metodologia de investigação em ciências sociais e humanas: Teoria e Prática. 2 ed. Coimbra: Edições Almedina, 2018.

DANDOLINI, A. H. P.. Fungos: estudo sobre suas contribuições à biosfera. Paranavaí: Universidade Estadual do Paraná, 2013.

ESPINOZA, A. M.. Ciências na escola: novas perspectivas para a formação dos alunos. São Paulo: Ática, 2010. 
FRANCO, M. A. S.. Pedagogia da pesquisa-ação. Educação e Pesquisa, São Paulo, v.31, n.3, p.483-502, 2005.

GIMENES, L. J.. Fungos Basidiomicetos técnicas de coleta, isolamento e subsídios para processos biotecnológicos. São Paulo: Instituto de Botânica, 2010.

GUIMARÃES, L.. Ensino de Ciências e experimentação: reconhecendo obstáculos e possibilidades das atividades investigativas em uma formação continuada. Revista Thema, v.15, n.3, 2018. DOI:

http://dx.doi.org/10.15536/thema.15.2018.1164-1174.991

GONDIM, S. M. G.. Grupos focais como técnica de investigação qualitativa: desafios metodológicos. Salvador: Paideia, 2003

LUDKE, M.; ANDRÉ, M. E. D. A.. Pesquisa em Educação: Abordagens qualitativas. Rio de Janeiro: E. P. U., 2017.

MOÇO, A.; MONROE, C.. 5 etapas para realizar uma boa pesquisa escolar. Nova Escola, 2010.
PEZARINI, A. R.; MACIEL, M. D.. As dimensões da argumentação no Ensino de Ciências em pesquisas de 2007 a 2017: um olhar para a caracterização e para as ferramentas metodológicas para estudar esta temática. AmazôniaRevista de Educação em Ciências e Matemáticas, v.14, n.32, 2018.

SILVA, C. E.. Elaboração de TCC e publicação de artigos: for estarters. Aracaju: Sustenere, 2018.

SILVA, E. D.. A importância das atividades experimentais na educação. Rio de Janeiro, 2017.

SANTOS, E. R. D. S.. Material complementar do livro Sistemática Vegetal I: Fungos. Florianópolis, 2015.

STOLARSKI, M. C.; DORIGO, A. B.; CUNHA F. B.; OLIVEIRA, S.. Boas práticas de manipulação de alimentos. Curitiba: SEED, 2015.

TRIPP, D.. Pesquisa-ação: uma introdução metodológica. São Paulo: Educação e pesquisa, v.31, n.3, p.443-466, 2005.

A CBPC - Companhia Brasileira de Produção Científica (CNPJ: 11.221.422/0001-03) detém os direitos materiais desta publicação. Os direitos referem-se à publicação do trabalho em qualquer parte do mundo, incluindo os direitos às renovações, expansões e disseminações da contribuição, bem como outros direitos subsidiários. Todos os trabalhos publicados eletronicamente poderão posteriormente ser publicados em coletâneas impressas sob coordenação da Cognitionis Publishing, da Companhia Brasileira de Produção Científica e seus parceiros autorizados. Os (as) autores (as) preservam os direitos autorais, mas não têm permissão para a publicação da contribuição em outro meio, impresso ou digital, em português ou em tradução. 